\title{
Imaging Measurements and LES-CMC Modeling of a Partially-Premixed Turbulent Dimethyl Ether/Air Jet Flame
}

\author{
Bruno Coriton ${ }^{1}$, M. Zendehdel ${ }^{2}$, S. Ukai ${ }^{2}$, A. Kronenburg ${ }^{2}$, O. T. Stein ${ }^{2}$, \\ Seong-Kyun $\mathrm{Im}^{3}$, Mirko Gamba ${ }^{3,+}$, and Jonathan H. Frank ${ }^{1, *}$ \\ ${ }^{1}$ Combustion Research Facility, Sandia National Laboratories, Livermore, CA 94551, USA \\ ${ }^{2}$ Institut für Technische Verbrennung, Universität Stuttgart, 70174 Stuttgart, Germany \\ ${ }^{3}$ Dept. of Mechanical Engineering, Stanford University, Stanford, CA 94305 USA \\ ${ }^{+}$(Current Address) Dept. of Aerospace Engineering, University of Michigan, Ann Arbor, MI 48109

\section{Colloquium on Turbulent Flames} \\ * Corresponding Author: Jonathan H. Frank \\ P.O. Box 969, MS. 9053 \\ Livermore, CA 94551, USA \\ Fax: (925) 294-2595 \\ jhfrank@sandia.gov
}

Color reproduction charges will be paid for those figures that in the revision stage cannot be reproduced in black and white without loss of clarity.

\begin{tabular}{|c|c|c|c|c|c|}
\hline \multirow[t]{3}{*}{$\begin{array}{l}\text { main text } \\
\text { references }\end{array}$} & 28 & & & \multirow{3}{*}{$\begin{array}{l}\text { equiv. words } \\
\text { Caption }\end{array}$} & \multirow{3}{*}{\begin{tabular}{|l}
4263 \\
524 \\
Figure total
\end{tabular}} \\
\hline & Figure & & & & \\
\hline & height [mm] & \# columns & equiv. words & & \\
\hline Fig. 1 & 44 & 1 & 120 & 19 & 139 \\
\hline Fig. 2 & 100 & 1 & 242 & 30 & 272 \\
\hline Fig. 3 & 85 & 1 & 208 & 18 & 226 \\
\hline Fig. 4 & 85 & 1 & 208 & 13 & 221 \\
\hline Fig. 5 & 85 & 1 & 208 & 13 & 221 \\
\hline Fig. 6 & 55 & 1 & 143 & 15 & 158 \\
\hline All figures & & & & & 1237 \\
\hline Total & & & & & 6025 \\
\hline
\end{tabular}




\title{
Imaging Measurements and LES-CMC Modeling of a
}

\section{Partially-Premixed Turbulent Dimethyl Ether/Air Jet Flame}

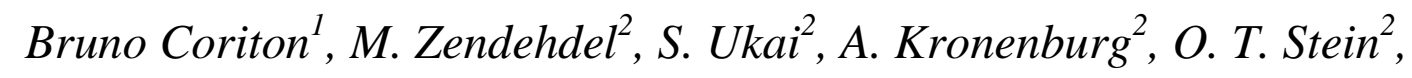 \\ Seong-Kyun $\mathrm{Im}^{3}$, Mirko Gamba ${ }^{3,+}$, and Jonathan H. Frank ${ }^{1, *}$
}

\author{
${ }^{1}$ Combustion Research Facility, Sandia National Laboratories, Livermore, CA 94551, USA \\ ${ }^{2}$ Combustion Institut fuer Technische Verbrennung, Universitaet Stuttgart, 70174 Stuttgart, Germany \\ ${ }^{3}$ Dept. of Mechanical Engineering, Stanford University, Stanford, CA 94305 USA \\ ${ }^{+}$(Current Address) Dept. of Aerospace Engineering, University of Michigan, Ann Arbor, MI 48109
}

Turbulent dimethyl ether (DME) jet flames provide a canonical flame geometry for studying turbulence-flame interactions in oxygenated fuels and for developing predictive models of these interactions. The development of accurate models for DME/air flames would establish a foundation for studies of more complex oxygenated fuels. We present a joint experimental and computational investigation of the velocity field and $\mathrm{OH}$ and $\mathrm{CH}_{2} \mathrm{O}$ distributions in a piloted, partially-premixed turbulent DME/air jet flame with a jet exit Reynolds number, $R e_{D}$, of 29,300. The turbulent DME/air flame is analogous to the well-studied, partially-premixed methane/air jet flame, Sandia Flame D, with identical stoichiometric mixture fraction, $\xi_{s t}=0.35$, and bulk jet exit velocity, $V_{b u l k}=45.9 \mathrm{~m} / \mathrm{s}$. Measurements include particle image velocimetry (PIV) and simultaneous $\mathrm{CH}_{2} \mathrm{O}$ and $\mathrm{OH}$ 
laser-induced fluorescence (LIF) imaging. Simulations are performed using a large eddy simulation combined with conditional moment closure (LES-CMC) on an intermediate size grid of 1.3 million cells. Overall, the downstream evolution of the mean and RMS profiles of velocity, $\mathrm{OH}$, and $\mathrm{CH}_{2} \mathrm{O}$ are well predicted, with the largest discrepancies occurring for $\mathrm{CH}_{2} \mathrm{O}$ at $x / D=20-25$. LES-CMC simulations employing two different chemical reaction mechanisms (Kaiser et al., 2000 and Zhao et al., 2008) show approximately a factor of two difference in the peak $\mathrm{CH}_{2} \mathrm{O}$ mole fractions, whereas $\mathrm{OH}$ mole fractions are in good agreement between the two mechanisms. The single-shot LIF measurements of $\mathrm{OH}$ and $\mathrm{CH}_{2} \mathrm{O}$ show a wide range of separation distances between the spatial distributions of these intermediate species with gaps on the order of millimeters. The intermittency in the overlap between these species indicates that the consumption rates of formaldehyde by $\mathrm{OH}$ in a turbulent DME/air jet flame may be highly intermittent with significant departures from flamelet models.

Keywords: DME, Turbulent Jet Flames, PIV, LES-CMC, TNF workshop.

\section{Introduction}

Dimethyl ether (DME) is a promising clean fuel for compression ignition (CI) engines. DME's high cetane number and easy vaporization also make it a potential fuel candidate for homogeneous charge compression ignition (HCCI) engines [1]. DME-fueled engines have the potential to significantly reduce $\mathrm{CO}$ and soot emission levels because of the presence of oxygen in the DME molecule $\left(\mathrm{CH}_{3}-\mathrm{O}-\mathrm{CH}_{3}\right)$ and the absence of a carbon-carbon bond [2,3]. Despite the potential of DME 
as a clean fuel, appropriate combustion technologies must be developed and a fundamental understanding of the interplay between DME chemistry and turbulence is required.

Turbulent jet flames provide a canonical geometry for the study of turbulence-flame interactions and have been used in the development and testing of turbulent combustion models. Within the context of the International Workshop on Measurements and Computation of Turbulent Non-Premixed Flames (TNF) [4], piloted methane/air jet flames (Sandia flames C-to-F) spanning Reynolds number of approximately 13,000 to 43,000 have been used extensively for experimental studies (e.g. $[5,6])$ and for model development (e.g. $[7,8])$. DME flames represent a step forward in chemical complexity and a good starting point for systematic studies of turbulent flames with oxygenated fuels.

The present study is a joint experimental and computational investigation of the structure of a piloted, partially-premixed turbulent DME/air jet flame with respect to the $\mathrm{OH}$ and $\mathrm{CH}_{2} \mathrm{O}$ fields. In DME combustion, the production of $\mathrm{CH}_{2} \mathrm{O}$ is directly linked to the fuel consumption pathway, which can result in significantly different distributions of $\mathrm{CH}_{2} \mathrm{O}$ in DME jet flames than in methane jet flames [9]. We investigate the ability of an intermediate-resolution LES calculation to capture the distributions of $\mathrm{CH}_{2} \mathrm{O}$ and $\mathrm{OH}$, and we compare results of simulations using two different chemical mechanisms for DME combustion.

The turbulent partially-premixed DME/air jet flame with a jet exit Reynolds number of 29,300 is analogous to the well-studied $\mathrm{CH}_{4} /$ air Sandia Flame $D[4,5]$ with identical bulk jet exit velocity, $V_{b u l k}$, of $45.9 \mathrm{~m} / \mathrm{s}$ and stoichiometric mixture fraction, $\xi_{s t}$, of 0.35 . Recently, Fuest et al. [10] discussed the diagnostics challenges of Raman/Rayleigh scattering measurements in DME flames. In the present study, we use laser-induced fluorescence (LIF) imaging to measure the topology of the $\mathrm{OH}$ and $\mathrm{CH}_{2} \mathrm{O}$ fields complemented by stereoscopic particle image velocimetry (SPIV) measurements of the velocity field. 
The turbulent DME/air jet flame is simulated using a large eddy simulation combined with conditional moment closure, LES-CMC. LES resolves the largest turbulent structures and relies on modeling of the unresolved sub-grid scales. The LES approach has been successfully used to model the related $\mathrm{CH}_{4} /$ air piloted jet flame series employing various different turbulent combustion models by, among others, Refs. $[8,11]$. CMC is based on the notion that fluctuations of the reacting scalars are closely linked to the fluctuations of a small set of scalar reference variables [12]. For non-premixed flames, the mixture fraction is commonly used as the reference variable. LES-CMC was successfully used to predict a number of gas flames [13-15] and was recently extended to multi-phase combustion $[16,17]$. A previous application of LES-CMC to the piloted $\mathrm{CH}_{4} /$ air flame series was reported by Navarro-Martinez et al. [18], where good agreement with the experimental data was found and closure models for the unclosed terms in the LES-CMC equations were proposed. In the present study, the previously employed LES-CMC model is used without modification of any of the sub-models or model parameters, and applied to the piloted DME/air jet flame to test its predictive capability under modified combustion chemistry.

\section{Experimental Methods}

\subsection{Piloted Jet Burner and Experimental Conditions}

The partially-premixed DME/air flame was stabilized on a piloted jet burner with a jet diameter of $7.45 \mathrm{~mm}$, a pilot annulus of $18.2 \mathrm{~mm}$ and a coflow diameter of $254 \mathrm{~mm}$. The jet mixture was composed of a 4:1 volume ratio of air to DME and was injected at a flow rate of 120 LPM at $294 \mathrm{~K}$. The annular pilot reactant mixture of equivalence ratio $\varphi_{\text {pilot }}=0.6$ was composed of $0.29 \mathrm{LPM}$ of $\mathrm{C}_{2} \mathrm{H}_{2}, 1.18 \mathrm{LPM}$ of $\mathrm{H}_{2}, 0.40 \mathrm{LPM}$ of $\mathrm{CO}_{2}, 0.52 \mathrm{LPM}$ of $\mathrm{N}_{2}$ and $10.95 \mathrm{LPM}$ of air. The energy release of the pilot was approximately $2 \%$ of the jet mixture, as opposed to $6 \%$ in the Sandia $\mathrm{CH}_{4} /$ air flames. The burner was 
surrounded with an air coflow with an initial velocity of $0.9 \mathrm{~m} / \mathrm{s}$, which was monitored using a hot-film anemometer.

\subsection{Stereo Particle Image Velocimetry (SPIV)}

The SPIV system consisted of a dual-head Nd:YAG laser that provided a pair of laser pulses $(\lambda=532 \mathrm{~nm})$ separated by $4.0 \mu$ s at a repetition rate of $5 \mathrm{~Hz}$. A combination of cylindrical lenses was used to expand and shape the laser beam into an approximately $1.0 \mathrm{~mm}$ thick laser sheet. The jet and coflow were seeded with $0.3 \mu \mathrm{m}$ aluminum oxide particles for the PIV measurements. Particle light scattering was imaged onto a pair of interline transfer CCD cameras mounted on the same side of the laser sheet at 23 degrees with respect to the normal of the imaging plane. The cameras were equipped with Nikon 105-mm f/2.8 macro lenses and Scheimpflug mounts to compensate for the displacement of the imaging plane. A narrow-bandpass interference filter centered at 532nm was placed in front of each lens to reduce interference from flame luminosity.

Velocity vectors were calculated using an iterative cross-correlation processing algorithm with a final interrogation window size of $32 \times 32 \mathrm{px}^{2}$ and $50 \%$ overlap, resulting in a vector spacing of $237 \mu \mathrm{m}$. A universal outlier detection algorithm was used to eliminate spurious vectors that were discarded in the computation of the velocity statistics. No smoothing was applied to the instantaneous velocity vector fields.

\subsection{Simultaneous $\mathrm{OH}-\mathrm{LIF}$ and $\mathrm{CH}_{2} \mathrm{O}$-LIF Imaging}

Laser-induced fluorescence of $\mathrm{OH}$ was excited by the frequency doubled output of a Nd:YAGpumped dye laser tuned to the $\mathrm{Q}_{1}(6)$ line $(\lambda=283.01 \mathrm{~nm}, \sim 1.2 \mathrm{~mJ} / \mathrm{pulse})$ of the $\mathrm{A}^{2} \Sigma^{+} \leftarrow \mathrm{X}^{2} \Pi^{+}\left(\mathrm{v}^{\prime}=1, \mathrm{v}^{\prime \prime}=0\right)$ band of $\mathrm{OH}$. The $\mathrm{OH}$ fluorescence emission from the $\mathrm{A}-\mathrm{X}(0,0)$ and $(1,1)$ bands was imaged onto an 
intensified CCD camera using a UV-camera lens (f.l. $=45 \mathrm{~mm}, \mathrm{f} / 1.8)$ with color glass filters (UG11 and WG305) to block interferences.

Laser-induced fluorescence of formaldehyde was excited by the third harmonic of an injection seeded Nd:YAG laser ( $\sim 42 \mathrm{~mJ} / \mathrm{pulse})$. The diode seed laser was temperature-tuned to $\lambda=354.83 \mathrm{~nm}$ to excite overlapping transitions in the $4_{0}^{1}$ band of the $\tilde{A}^{1} A_{2} \leftarrow \tilde{X}^{1} A_{1}$ system. The use of an injection seeded laser increased the LIF signal by approximately a factor two with respect to using an unseeded Nd:YAG laser. The narrow linewidth of the seeded laser also simplified the simulation of formaldehyde LIF signals since fewer transitions were excited than with an unseeded laser. The laser beam was horizontally polarized to eliminate interferences from Rayleigh or Raman scattering. The $\mathrm{CH}_{2} \mathrm{O}$ fluorescence emission was imaged onto an intensified CCD camera using a medium-format camera lens, an AR-coated singlet (f.1.=-400 mm), and a 35-mm format lens. A color glass filter (GG375) in the imaging system blocked elastic scattering from the laser and transmitted the $\mathrm{CH}_{2} \mathrm{O}-\mathrm{LIF}$ signal.

The OH-LIF and $\mathrm{CH}_{2} \mathrm{O}$-LIF measurements were corrected for spatial variations in the average beam profiles and the throughput of the imaging systems. Shot-to-shot fluctuations were negligible for the subsection of the laser beams that were used for LIF imaging. The LIF signals were not corrected for local variations in quenching rates and ground-state Boltzmann fraction populations. The projected pixel sizes of the detection systems were $53 \mu \mathrm{m}$ for OH-LIF imaging and $19 \mu \mathrm{m}$ for $\mathrm{CH}_{2} \mathrm{O}-\mathrm{LIF}$ imaging. The $\mathrm{CH}_{2} \mathrm{O}-\mathrm{LIF}$ and $\mathrm{OH}-\mathrm{LIF}$ images were filtered using $3 \times 3 \mathrm{px}^{2}$ Gaussian smoothing kernel.

\section{Numerical Methods}

\subsection{LES-CMC Modeling}

Combustion was modeled by coupling the CMC method with LES, as described in Ref. [18], with the CMC grid coarser than the LES mesh. The conditional moments of the reacting species mass 
fractions and enthalpy were solved conditional on mixture fraction. LES-CMC requires a number of closure assumptions. Following Ref. [18], the shape of the filtered-density function (FDF) was presumed to be a $\beta$-function and the conditional fluctuations were assumed to be negligible in the modeling of the conditional reaction source terms (first-order CMC). The conditionally-filtered scalar dissipation, velocity, and diffusivity required in the CMC equations were modeled as simple ensemble averages of the filtered dissipation, velocity and turbulent diffusivity, conditioned on filtered mixture fraction within a CMC cell. DME/air combustion chemistry was represented by two different reaction mechanisms, namely Fischer/Kaiser et al. $[19,20]$ consisting of 78 species and 351 reactions and Zhao et al. [21] employing 55 species and 290 reactions. These two mechanisms are referred to as Kaiser and Zhao mechanisms, respectively.

A density-weighted Favre-filter was used to derive the filtered Navier-Stokes equations. The subgrid stresses were modeled based on the eddy viscosity approach and the turbulent viscosity was modeled using Smagorinsky's model with the model constant adjusted dynamically [22]. To account for turbulent mixing between fuel and oxidizer, we solved an additional mixture fraction transport equation solved with the subgrid scalar flux modelled by assuming gradient diffusion and a turbulent Schmidt number of 0.4. The in-house LES-CMC code BOFFIN was used for the simulations. BOFFIN uses the finite-volume method to solve the governing equations, where the mass and momentum equations are discretized by second-order central differences, whereas the convective transport of the bounded scalars is discretized by a total variation diminished (TVD) scheme and time integration is of second order. A SIMPLE-type predictor-corrector procedure with pressure smoothing is employed and the governing variables are stored at the cell centers (co-located grid). Further details on the code can be found in Ref.[23].

A stretched Cartesian mesh was employed, where the computational domain of 10Dx10D at the inlet plane was expanded towards the domain outlet to account for the radial jet spreading. The domain 
extended over 60D in the downstream direction. A LES grid with $72 \times 72 \times 240$ cells was used, according to previous grid independence studies in the $\mathrm{CH}_{4}$ /air flame series. A CMC grid with $2 \times 2 \times 60$ cells was employed, where again prior experience from the $\mathrm{CH}_{4} /$ air flame shows that this shear-layer dominated flame can be captured with a relatively coarse CMC resolution in the cross-stream direction. At the nozzle exit plane, artificially generated turbulence was superimposed on the mean velocity profile following Klein et al. [24], which required a nominal integral length scale and Reynolds-stress tensor. The integral scale was set to $0.25 \mathrm{D}$ and the Reynolds-stress tensor was set to match the mean and rootmean-squared (RMS) axial velocity profiles that were measured $1 \mathrm{~mm}$ above the nozzle exit. With this constraint of matching the velocity RMS profile at the most upstream measurement location, the turbulent evolution along the jet is mainly governed by the resolved shear, and the jet break-up can be captured well. Coflow inflow conditions were matched to the experiments and a zero-gradient boundary condition was set at the exit plane. The simulations were run in parallel using MPI for approximately 4 weeks on 48 AMD-Opteron cores to achieve statistical convergence.

\subsection{Simulation of LIF Signals}

Conversion of the OH-LIF and $\mathrm{CH}_{2} \mathrm{O}-\mathrm{LIF}$ signals into species concentrations was not performed since it would have required simultaneous measurements of temperature and major species concentrations, which were unavailable in the present experiments. Instead, the LIF measurements were compared with simulated OH-LIF and $\mathrm{CH}_{2} \mathrm{O}$-LIF signals that were calculated using instantaneous realizations of the temperature and species mole fractions from the LES-CMC results. Simulation of the LIF signals requires knowledge of the temperature dependence of the Boltzmann fraction population of the ground state and the collisional quenching rates of the excited state. For simulating OH-LIF signals, we calculated the Boltzmann fraction population of the $Q_{1}(6)$ transition of the $A^{2} \Sigma^{+} \leftarrow X^{2} \Pi^{+}$ $\left(\mathrm{v}^{\prime}=1, \mathrm{v}^{\prime \prime}=0\right)$ band and the quenching rates using the quenching cross sections from Tamura et al. [25]. 
The simulation of formaldehyde LIF signals is more complex than $\mathrm{OH}$ because of the high spectral density of transitions and the lack of available quenching cross sections at flame temperatures. The density of active transitions increases at elevated temperatures. The temperature dependent populations of the lower states of the relevant overlapping transitions in the $4{ }_{0}^{1}$ band of the $\tilde{A}^{1} A_{2} \leftarrow \tilde{X}^{1} A_{1}$ system were calculated using Asyrot spectral simulation software [26]. For the quenching rate calculations, we compared two different models for the temperature dependence of quenching cross-sections. In one model, the quenching cross-sections of all species were considered to be independent of temperature, and in the second model a power law of $T^{-0.5}$ was used [27]. An example of the predicted $\mathrm{CH}_{2} \mathrm{O}-\mathrm{LIF}$ signals using the $T^{-0.5}$ dependence of quenching cross-sections is shown in Fig. 1 for a laminar counterflow flame calculation with the same fuel stream composition as the turbulent jet flame. The laminar flame calculation was performed using Chemkin OPPDIF [28] and the Zhao and Kaiser mechanisms for a strain rate of $a=200 \mathrm{~s}^{-1}$. The $\mathrm{CH}_{2} \mathrm{O}$-LIF profiles are biased towards lower temperatures and their peaks are shifted by approximately $0.25 \mathrm{~mm}$ with respect to the $\mathrm{CH}_{2} \mathrm{O}$ mole fraction peaks. The peak $\mathrm{CH}_{2} \mathrm{O}-\mathrm{LIF}$ signal for the Zhao mechanism is approximately $34 \%$ larger than for the Kaiser mechanism, and the peak mole fractions differ by $29 \%$. The peak $\mathrm{CH}_{2} \mathrm{O}-\mathrm{LIF}$ signals using temperature-independent quenching cross sections (not shown) were shifted by $0.04 \mathrm{~mm}$ towards lower temperatures with respect to the $\mathrm{CH}_{2} \mathrm{O}-\mathrm{LIF}$ signals using the $T^{-0.5}$ dependence. For comparisons of the LES calculations with measurements in the turbulent flame, we used the quenching model with $T^{-0.5}$ dependence, which provided slightly better agreement with the measured radial profiles of $\mathrm{CH}_{2} \mathrm{O}-$ LIF signals than the temperature independent model. An example of instantaneous measured and computed LIF signals in the turbulent jet flame is shown in Fig. 2. 


\section{Results and Discussion}

\subsection{Velocity Statistics}

Figure 3 shows radial profiles of the measured and computed, mean and RMS velocities from $x / D=5$ to 25 . In addition to temporal averaging over a large number of steady-state realizations, the statistical convergence of the 3D-LES velocity data was improved by averaging along the circumference of the axisymmetric configuration. The velocity profiles for the simulations using different mechanisms are virtually identical. The mean measured and computed velocity profiles match very well at most downstream positions, despite some minor off-axis discrepancies. The measured and computed RMS velocities show good overall agreement, but some discrepancies are apparent. The centerline RMS velocities match at $x / D=5$, apart from a slight inward shift of the LES data, which may stem from difficulties in resolving the steep gradients in the upstream shear layer. The measurements show a slower increase in the centerline RMS velocity as a function of downstream position. The measured and computed locations of the peak RMS velocity are also slightly different near the nozzle but show closer agreement with increasing downstream position. Profiles of the mean and RMS radial velocity (not shown) agreed well with the LES-CMC simulations.

\section{2. $\mathrm{OH}$ and $\mathrm{CH}_{2} \mathrm{O}$ Field Statistics}

The downstream evolution of the measured and computed radial profiles of $\mathrm{OH}-\mathrm{LIF}$ and $\mathrm{CH}_{2} \mathrm{O}-\mathrm{LIF}$ signals in the turbulent jet flame are compared. The computed LIF signals from the LES-CMC results from the Zhao and Kaiser mechanisms were calculated using 656 and 555 instantaneous realizations, respectively. For each realization, the LIF signals were computed from the mole fractions of $\mathrm{OH}$, $\mathrm{CH}_{2} \mathrm{O}$, major species, and the temperature using the approach described in Section 3.2. In Figs. 4 and 5, the comparisons of the measured and computed LIF signals are initiated by normalizing the mean and RMS profiles by the peak value of the corresponding mean LIF signal at $x / D=5$. Note that the mean 
and RMS LIF signals for the Kaiser mechanism were normalized with respect to the peak of the mean LIF profiles for the Zhao mechanism at $x / D=5$ to facilitate comparison of the mechanisms.

The mean OH-LIF profiles in Fig. 4 show the progression of the radial distribution of $\mathrm{OH}$ from $x / D=5$ to 25 , with negligible differences between the two mechanisms. Overall, the agreement between the experiment and simulation is quite good. At $x / D=5$, the peaks of the measured and simulated profiles of mean OH-LIF signal are located near $r / D=1$. The experiment and simulation show a similar progression of increasing width and radial location of the peaks as a function of downstream position. The computed mean OH-LIF profiles are slightly more skewed towards larger radial positions, i.e. toward the coflowing stream of air. The peak location of the measured mean OH-LIF profile is slightly closer to the jet axis for $x / D=5-15$. The measured and computed RMS profiles exhibit similar bimodal structure at $x / D=5-15$ with the measured values somewhat larger than the computed profiles. The measured RMS OH-LIF signals are consistently higher at the outer edge of the profiles than the simulated RMS OH-LIF signals. Overall, the agreement in the radial position and shape of the RMS OH-LIF profiles is quite good.

The measured and computed $\mathrm{CH}_{2} \mathrm{O}$-LIF profiles are shown in Fig. 5. The measured profiles are plotted twice in Fig. 5 with separate normalization of the measured profiles for each reaction mechanism at $x / D=5$. Overall, the computed $\mathrm{CH}_{2} \mathrm{O}$-LIF signals for both reaction mechanisms are in good agreement with the normalized experimental data, with no significant improvement of using one reaction mechanism over the other. The mean $\mathrm{CH}_{2} \mathrm{O}$-LIF radial profiles have a peak off the jet centerline for axial locations $x / D=5-15$ and transition to having a peak on the jet axis at $x / D=20$ and 25. As the axial location increases, the measured $\mathrm{CH}_{2} \mathrm{O}$-LIF profiles spread faster and extend to increasingly larger radial positions than the computed $\mathrm{CH}_{2} \mathrm{O}$-LIF profiles. Preliminary statistics from LES-CMC simulations with reduced grid stretching and significantly finer cells in the downstream regions indicate slightly wider mean radial distributions of $\mathrm{CH}_{2} \mathrm{O}$; however, this finding requires further 
investigations. The measured and computed radial profiles of $\mathrm{RMS} \mathrm{CH}_{2} \mathrm{O}-\mathrm{LIF}$ signals evolve quite similarly with bimodal distributions at $x / D=5$ and 10 and single off-axis peaks at $x / D=15-25$. Similar to the mean profiles, the measured RMS profiles expand in the radial direction more than the computed profiles as the downstream position increases. Similar trends were observed when simulating $\mathrm{CH}_{2} \mathrm{O}-\mathrm{LIF}$ signals with temperature independent quenching cross sections.

The most noticeable difference between the $\mathrm{CH}_{2} \mathrm{O}$-LIF profiles using the different mechanisms is that the Zhao mechanism predicts a factor of approximately two higher peak $\mathrm{CH}_{2} \mathrm{O}$-LIF signals at all axial locations. This difference is not an artifact of comparing simulated LIF signals since a similar discrepancy is also observed in the LES predictions of $\mathrm{CH}_{2} \mathrm{O}$ mole fractions using the two mechanisms (not shown). The laminar flame calculations in Fig. 1 also show a discrepancy between the mechanisms. This discrepancy may stem from a difference between the relative contributions of unimolecular decomposition and the abstraction of a hydrogen atom from DME in the fuel consumption pathway of each mechanism. A reaction pathway analysis from the laminar flame calculations shows that the dominant production reaction for formaldehyde in both mechanisms is the decomposition of the methoxy-methyl radical via the reaction $\mathrm{CH}_{3} \mathrm{OCH}_{2}=\mathrm{CH}_{2} \mathrm{O}+\mathrm{CH}_{3}$. The production of the methoxymethyl radical from DME proceeds via abstraction of a hydrogen atom by reactions of DME with radicals, such as $\mathrm{H}, \mathrm{OH}, \mathrm{O}, \mathrm{CH}_{3}$. For both mechanisms, the dominant hydrogen atom abstraction reaction is $\mathrm{DME}+\mathrm{H}=\mathrm{CH}_{3} \mathrm{OCH}_{2}+\mathrm{H}_{2}$. However, the second most important DME consumption reaction differs for each mechanism. For the Kaiser mechanism, the second most important reaction is the unimolecular decomposition of DME via the reaction $\mathrm{DME}=\mathrm{CH}_{3}+\mathrm{CH}_{3} \mathrm{O}$. In contrast, the second most important reaction for the Zhao mechanism is hydrogen abstraction via DME $+\mathrm{CH}_{3}=\mathrm{CH}_{3} \mathrm{OCH}_{2}+\mathrm{CH}_{4}$. As a result, the production of the methoxy-methyl radical and subsequently formaldehyde may be enhanced in the Zhao mechanism. 


\subsection{Structural Analysis of $\mathrm{OH}$ and $\mathrm{CH}_{2} \mathrm{O}$ Distributions}

A reaction rate analysis of formaldehyde consumption shows that the second most significant consumption reaction is $\mathrm{CH}_{2} \mathrm{O}+\mathrm{OH}=\mathrm{HCO}+\mathrm{H}_{2} \mathrm{O}$, with the first and third most significant being reactions of formaldehyde with atomic hydrogen and methyl radicals, respectively. The laminar flame calculations in Fig. 1 show that the tails of the formaldehyde and $\mathrm{OH}$ distributions slightly overlap in the region where formaldehyde is consumed. In contrast, the single-shot measurements and the LES realization in Fig. 2 show that there can be wide separations between the $\mathrm{OH}$ layer and the outer boundary of the formaldehyde distribution in many regions of the turbulent jet flame. The single-shot measurement at $x / D=5$ (bottom right image) shows that a significant portion of the formaldehyde layer is in close proximity to the $\mathrm{OH}$ layer on the right-hand side, although a pocket with a larger gap appears in the upper region of that image. The distributions of formaldehyde and $\mathrm{OH}$ evolve with downstream position. The formaldehyde distribution fills in along the centerline and broadens to increasing radial positions, and the $\mathrm{OH}$ layer broadens and becomes increasingly convoluted. All of the single-shot measurements at $x / D=5-25$ show thin layers of formaldehyde extending away from the jet centerline such that they are in close proximity to the $\mathrm{OH}$ layer. At the farthest downstream positions, there is often a significant gap between the outer boundary of the formaldehyde distribution and the inner boundary of the $\mathrm{OH}$ layer.

To quantify the size of this gap on a statistical basis, we analyzed 700 simultaneous OH-LIF and $\mathrm{CH}_{2} \mathrm{O}$-LIF images at each downstream location and measured the radial separation distance between the outer boundary of the $\mathrm{CH}_{2} \mathrm{O}$-LIF distribution and the inner boundary of the OH-LIF layer. These boundaries were identified using isocontours of the LIF signals. The measurement was performed in each image along every eighth row of pixels, which corresponded to a vertical sampling of approximately $150 \mu \mathrm{m}$. Figure 6 shows the probability density function (PDF) of the $\mathrm{OH}-\mathrm{CH}_{2} \mathrm{O}$ 
separation distance as a function of axial location. The observed trends in the PDFs are insensitive to the values of the isocontours that were used to identify the boundaries of the LIF signals. The PDFs, which have a bin size of $0.25 \mathrm{~mm}$, show that the most probable separation distance is less than $0.50 \mathrm{~mm}$ at all axial locations. The small probability of negative separation distances corresponds to locations where there is a slight overlap between the $\mathrm{OH}$ and $\mathrm{CH}_{2} \mathrm{O}$ LIF signals. The PDFs are asymmetric with tails that extend towards larger separation distances. There is a consistent progression of monotonically increasing probability of large gaps as a function of downstream location. At $x / D=5$, the tail of the PDF extends to a maximum gap of approximately $3.0 \mathrm{~mm}$, whereas at $x / D=25$ the gap sizes are as large as $10 \mathrm{~mm}$, which is approximately 1.3 nozzle diameters. The PDFs at $x / D=20$ and 25 diameters are very similar, suggesting that the distribution asymptotes near this location. The frequent lack of overlap in the instantaneous $\mathrm{OH}$ and $\mathrm{CH}_{2} \mathrm{O}$ distributions may produce significant intermittency in the consumption rate of $\mathrm{CH}_{2} \mathrm{O}$ by $\mathrm{OH}$ and may reduce the overall role of this reaction in the consumption of formaldehyde relative to that predicted by laminar flamelet models.

\section{Conclusions}

A joint experimental and computational study of a piloted, turbulent partially-premixed DME/air jet flame at a jet exit Reynolds number of 29,300 and a stoichiometric mixture fraction of 0.35 was performed with a focus on comparing the velocity, $\mathrm{CH}_{2} \mathrm{O}$, and $\mathrm{OH}$ fields. Velocity measurements were performed using stereo particle image velocimetry, and $\mathrm{CH}_{2} \mathrm{O}$ and $\mathrm{OH}$ were imaged using laser-induced fluorescence at downstream locations of $x / D=5-25$. LES-CMC calculations on a domain extending up to $x / D=60$ were performed using approximately 1.3 million cells. The results show that this moderate resolution simulation agrees well with the measurements and captures much of the evolution of the mean and RMS velocity field, as well as the $\mathrm{OH}$ and $\mathrm{CH}_{2} \mathrm{O}$ fields. The largest discrepancy between the 
simulations and measurements occurred at $x / D=20-25$, where the measured radial $\mathrm{CH}_{2} \mathrm{O}$ profiles extended to larger radial positions than the simulations. Preliminary results from LES-CMC simulations with a finer grid suggest that these differences may be partially due to the limited resolution of the present simulations.

To compare the LIF measurements with the LES-CMC calculations of $\mathrm{CH}_{2} \mathrm{O}$ and $\mathrm{OH}$, we used the LES-CMC results to simulate $\mathrm{CH}_{2} \mathrm{O}-\mathrm{LIF}$ and OH-LIF signals and then compared the simulated and measured LIF signals. The $\mathrm{CH}_{2} \mathrm{O}$-LIF quenching cross sections were modeled as both temperature independent and with a $T^{-0.5}$ power law dependence. The latter model provided closer agreement between the measured and simulated $\mathrm{CH}_{2} \mathrm{O}$-LIF profiles. Simulations using the Zhao and Kaiser DME mechanisms predicted very similar mean and RMS profiles of temperature, velocity, and OH. However, the Zhao mechanism predicted approximately a factor of two greater peak formaldehyde levels than the Kaiser mechanism. The LIF imaging measurements revealed that at many downstream locations, the instantaneous spatial distributions of these radicals can be separated by a significant gap on the order of millimeters. The LES results also showed gaps between the $\mathrm{OH}$ and $\mathrm{CH}_{2} \mathrm{O}$ distributions. These gaps may produce highly intermittent consumption rates of formaldehyde by $\mathrm{OH}$ and produce significant departures from flamelet models in turbulent jet flames.

\section{Acknowledgments}

The authors thank M.G. Mungal for contributions to the experiments, W.P. Jones for providing the original CFD routines, and E. Huang for technical assistance in the laboratory. The experimental research was supported by the U.S. Department of Energy, Office of Basic Energy Sciences, Division of Chemical Sciences, Geosciences, and Biosciences. Sandia National Laboratories is a multiprogram laboratory operated by Sandia Corporation, a Lockheed Martin Company, for the U.S. Department of Energy under contract DE-AC04-94-AL85000. The Stuttgart group acknowledges the financial support 
of DFG (grant no. KR3648/1-2), high-performance computing access to HLRS. S.K. Im and M. Gamba were supported by the Department of Energy under Award Number DE-FC52-08NA28614. 


\section{References}

[1] C. Arcoumanis, C. Bae, R. Crookes, E. Kinoshita, Fuel, 87 (2008) 1014-1030.

[2] X. Lu, D. Han, Z. Huang, Prog. Energy Combust. Sci., 37 (2011) 741-783.

[3] S.H. Park, C.S. Lee, Prog. Energy Combust. Sci., 39 (2013) 147-168.

[4] International Workshop on Measurement and Computation of Turbulent Nonpremixed Flames (TNF), http://www.sandia.gov/TNF

[5] R.S. Barlow, J.H. Frank, Proc. Combust. Inst., 27 (1998) 1087-1095.

[6] C. Schneider, A. Dreizler, J. Janicka, E.P. Hassel, Combust. Flame, 135 (2003) 185-190.

[7] J. Xu, S.B. Pope, Combust. Flame, 123 (2000) 281-307.

[8] A. Kempf, F. Flemming, J. Janicka, Proc. Combust. Inst., 30 (2005) 557-565.

[9] K.N. Gabet, H. Shen, R.A. Patton, F. Fuest, J.A. Sutton, Proc. Combust. Inst., 34 (2013) 1447-1454.

[10] F. Fuest, R.S. Barlow, J.-Y. Chen, A. Dreizler, Combust. Flame, 159 (2012) 2533-2562.

[11] H. Pitsch, H. Steiner, Phys. Fluids, 12 (2000) 2541-2554.

[12] A.Y. Klimenko, R.W. Bilger, Prog. Energy Combust. Sci., 25 (1999) 595-687.

[13] A. Garmory, E. Mastorakos, Proc. Combust. Inst., 33 (2011) 1673-1680.

[14] A. Triantafyllidis, E. Mastorakos, R.L.G.M. Eggels, Combust. Flame, 156 (2009) 2328-2345.

[15] S. Navarro-Martinez, A. Kronenburg, Flow Turbulence Combust, 87 (2011) 377-406.

[16] M. Mortensen, R.W. Bilger, Combust. Flame, 156 (2009) 62-72.

[17] S. Ukai, A. Kronenburg, O.T. Stein, Proc. Combust. Inst., 34 (2013) 1643-1650.

[18] S. Navarro-Martinez, A. Kronenburg, F. DiMare, Flow Turbulence Combust, 75 (2005) 245-274.

[19] S.L. Fischer, F.L. Dryer, H.J. Curran, Int. J. Chem. Kin., 32 (2000) 713-740.

[20] E.W. Kaiser, T.J. Wallington, M.D. Hurley, J. Platz, H.J. Curran, W.J. Pitz, C.K. Westbrook, J. Phys. Chem. A, 104 (2000) 8194-8206.

[21] Z. Zhao, M. Chaos, A. Kazakov, F.L. Dryer, Int. J. Chem. Kin., 40 (2008) 1-18.

[22] U. Piomelli, J. Liu, Phys. Fluids, 7 (1995) 839-848.

[23] W.P. Jones, F. di Mare, A.J. Marquis, LES-BOFFIN: User's Guide, 2002.

[24] M. Klein, A. Sadiki, J. Janicka, J. Comput. Phys., 186 (2003) 652-665.

[25] M. Tamura, P.A. Berg, J.E. Harrington, J. Luque, J.B. Jeffries, G.P. Smith, D.R. Crosley, Combust. Flame, 114 (1998) 502-514.

[26] R.H. Judge, D.J. Clouthier, Comp. Phys. Comm., 135 (2001) 293-311.

[27] P.H. Paul, H.N. Najm, Proc. Combust. Inst., 27 (1998) 43-50.

[28] R.J. Kee, F.M. Rupley, J.A. Miller, M.E. Coltrin, J.F. Grcar, E. Meeks, H.K. Moffat, A.E. Lutz, G. Dixon-Lewis, M.D. Smooke, J. Warnatz, G.H. Evans, R.S. Larson, R.E. Mitchell, L.R. Petzold, W.C.

Reynolds, M. Caracotsios, W.E. Stewart, P. Glarborg, in, Reaction Design, Inc., San Diego, CA, 2007. 


\section{Figures}

Figure 1. Laminar flame calculations of partially premixed DME/air flame using Zhao and Kaiser DME mechanisms and simulated $\mathrm{CH}_{2} \mathrm{O}-\mathrm{LIF}$ signal.

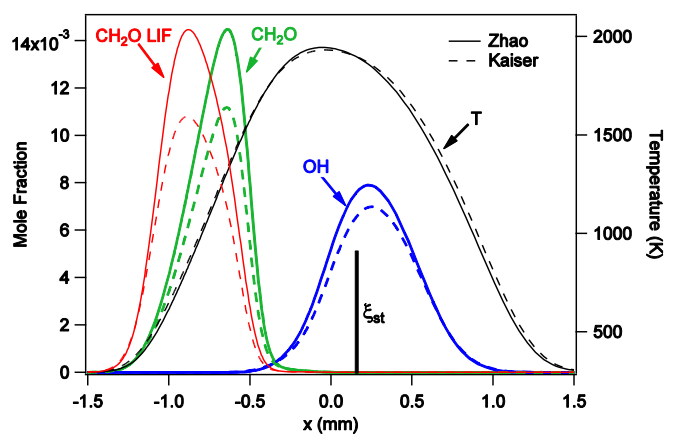

Figure 2. Composite image of computed $\mathrm{OH}-\mathrm{LIF}$ and $\mathrm{CH}_{2} \mathrm{O}-\mathrm{LIF}$ signals from an instantaneous realization of the LES calculations (left). Composite images of single-shot $\mathrm{OH}-\mathrm{LIF}$ and $\mathrm{CH}_{2} \mathrm{O}-\mathrm{LIF}$ measurements at different downstream positions (right).

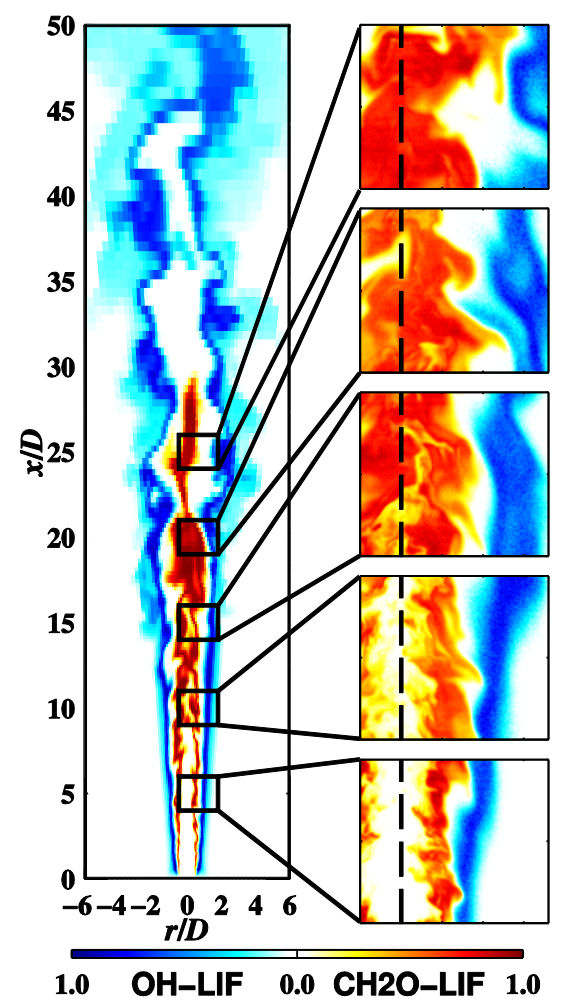


Figure 3. Measured (Exp.) and computed (LES) radial profiles of mean and RMS of axial velocity in DME jet flame.

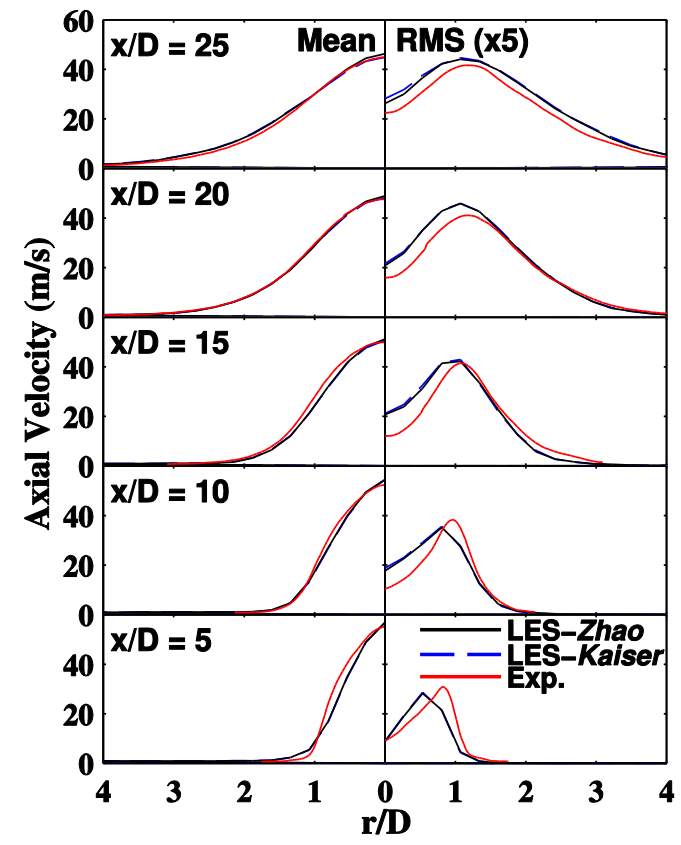

Figure 4. Measured (Exp.) and computed (LES) radial profiles of mean and RMS OH-LIF signals.

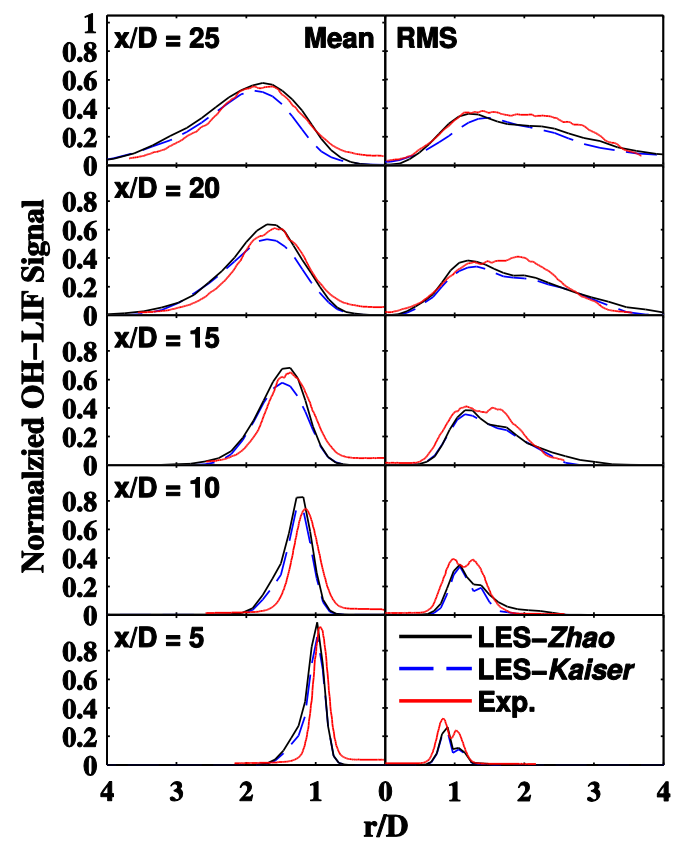




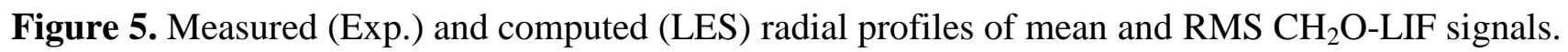

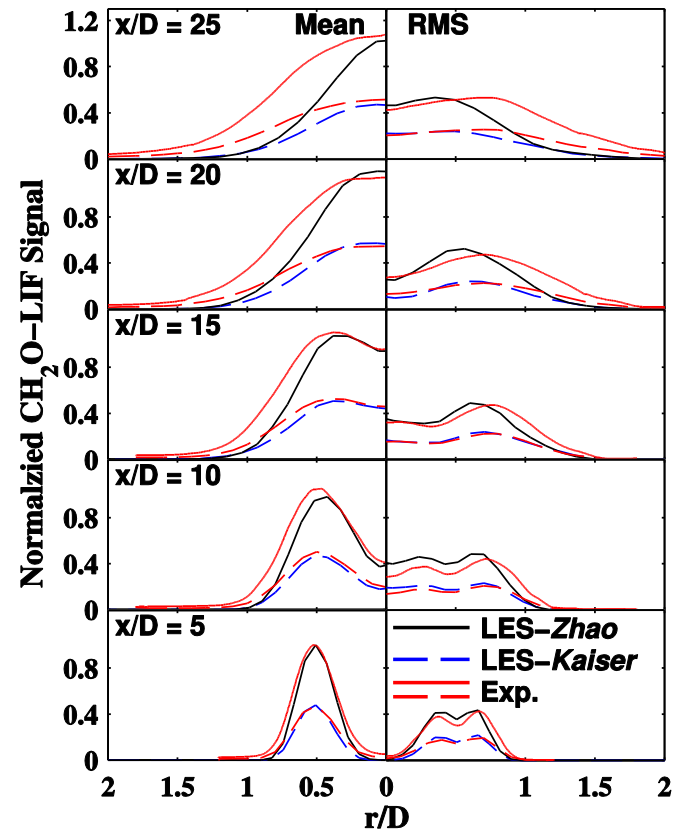

Figure 6. Probability density function of separation distance between the boundaries of the $\mathrm{CH}_{2} \mathrm{O}$ and $\mathrm{OH}$ fields.

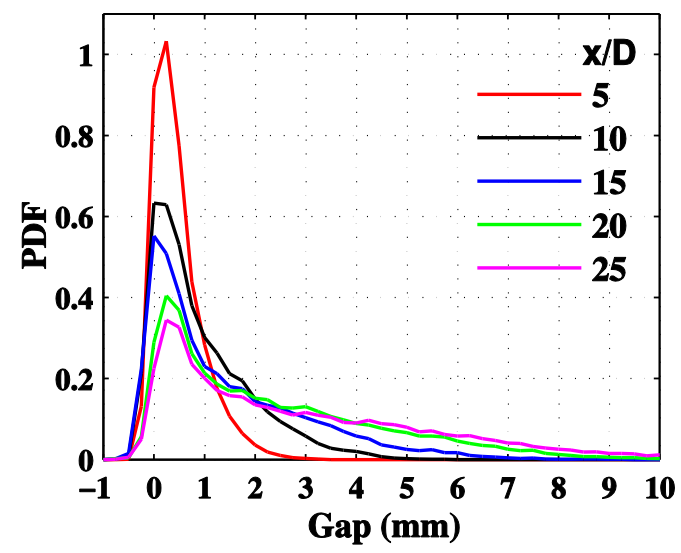




\section{List of Figure Captions}

Figure 1. Laminar flame calculations of partially premixed DME/air flame using Zhao and Kaiser DME mechanisms and simulated $\mathrm{CH}_{2} \mathrm{O}-\mathrm{LIF}$ signal.

Figure 2. Composite image of computed $\mathrm{OH}-\mathrm{LIF}$ and $\mathrm{CH}_{2} \mathrm{O}-\mathrm{LIF}$ signals from an instantaneous realization of the LES calculations (left). Composite images of single-shot $\mathrm{OH}-\mathrm{LIF}$ and $\mathrm{CH}_{2} \mathrm{O}-\mathrm{LIF}$ measurements at different downstream positions (right).

Figure 3. Measured (Exp.) and computed (LES) radial profiles of mean and RMS of axial velocity in DME jet flame.

Figure 4. Measured (Exp.) and computed (LES) radial profiles of mean and RMS OH-LIF signals.

Figure 5. Measured (Exp.) and computed (LES) radial profiles of mean and $\mathrm{RMS} \mathrm{CH}_{2} \mathrm{O}-\mathrm{LIF}$ signals.

Figure 6. Probability density function of separation distance between the boundaries of the $\mathrm{CH}_{2} \mathrm{O}$ and $\mathrm{OH}$ fields. 